\title{
Remembering Our Roots
}

\author{
Hyejung Chang, $\mathrm{PhD}$
}

Editor of Healthcare Informatics Research, Kyung Hee University, Seoul, Korea

This year marking the 30th anniversary of the Korean Society of Medical Informatics (KOSMI), the society that founded Healthcare Informatics Research, we felt that a look back on the growth of our journal over the years would be particularly meaningful. First published in 1995 as the official journal of KOSMI, the Journal of Korean Society of Medical Informatics grew to become one of Korea's foremost academic journals. In 2010, a move was made to expand our authorship and readership by meeting international guidelines and adopting English as the exclusive language of the journal, and it was at this time our journal adopted the name Healthcare Informatics Research (HIR) [1].

Since this move, our journal has grown to take on international roles in promoting healthcare informatics. With the aim of advancing the understanding of informatics and application systems in healthcare fields, our journal decided in the beginning of HIR that we would provide open access to our content, making high-quality healthcare informatics research available to researchers and practitioners within and beyond academia. Now in our 8th year, HIR has become a journal representing contributions from around the globe, with $45.2 \%$ of our manuscript submissions in 2017 coming from outside of Korea. We at HIR are pleased to see increasingly diverse communities come together to discuss developments in healthcare informatics and reflect on the implications they carry.

The results of our efforts have become even clearer in the last few years. First, in 2011, HIR became the first Asian

This is an Open Access article distributed under the terms of the Creative Commons Attribution Non-Commercial License (http://creativecommons.org/licenses/by$\mathrm{nc} / 4.0 /$ ) which permits unrestricted non-commercial use, distribution, and reproduction in any medium, provided the original work is properly cited.

(c) 2017 The Korean Society of Medical Informatics journal to be indexed in PubMed Central (PMC) in the medical informatics field. It was then listed in SCOPUS in 2013 and the Emerging Sources Citation Index (ESCI) in 2016 [2], which has increased our journal's visibility even further. In fact, citations of our journal have increased almost 500\% since 2011 [3].

HIR has also received significant attention domestically. In 2015, our journal was selected to receive an annual grant of $\$ 300,000$ for three years, an honor given to only three biomedical health journals in the country. This grant is given by the Korean Federation of Science and Technology Societies to bodies that have shown excellence in academic research. These developments, we feel, are a testament to our journal's international leadership in interdisciplinary research in the healthcare informatics field.

Moreover, we are witnessing the spread of our vision. We recently learned that Springer Publishing Co. has launched the Journal of Healthcare Informatics Research [4], a journal that focuses on the ICT aspects of the healthcare field. The substantial similarity of this journal title with HIR reflects the importance of the vision to which we are devoted. In 2009, the title "Healthcare Informatics Research" was chosen to emphasize a vision of research ultimately improving the healthcare systems that affect our everyday lives. Learning that other research bodies are pursuing this vision, we realize that our work has played a major role in the development of this new direction. This realization is more rewarding than any of our achievements thus far.

Thus, as we celebrate the anniversary of the roots of our journal, we have much on which to reflect. While we take pride in the work we have undertaken thus far, at the same time we must realize that we are only in the beginning of a new movement bridging research and practice in a field that affects the lives of millions around the world. Let us be both 
encouraged and challenged as we continue our commitment to our vision, a vision that we have fostered and ushered into the lives of millions around the world.

\section{References}

1. Healthcare Informatics Research [Internet]. Seoul, Korea: Korean Society of Medical Informatics; c2017 [cited at 2017 Oct 5]. Available from: http://www.e-hir.org/.

2. Chang H, Kim JA. Steps we have taken and steps we must take. Healthc Inform Res 2016;22(2):63-4.

3. SCImago Journal \& Country Rank for Healthcare Informatics Research [Internet]. Amsterdam: SCImago Lab; c2017 [cited at 2017 Oct 5]. Available from: http://www. scimagojr.com/journalsearch.php?q=21100242232\&tip= sid\&clean $=0$.

4. Journal of Healthcare Informatics Research [Internet]. Heidelberg: Springer; c2017 [cited at 2017 Oct 5]. Available from: http://www.springer.com/computer/informat ion+systems+and+applications/journal/41666. 